\title{
The Impact of Menstrual Disorder Towards Female University Students
}

\author{
By Azlan Ahmad Kamal , Zarizi Ab Rahman ${ }^{ \pm} \&$ Heldora Thomas ${ }^{*}$
}

\begin{abstract}
The purpose of this study is to study whether the menstrual disorder have impact on quality of life among female students which focus on physical and health education students from semester 1 until semester 8 in Uitm Puncak Alam, Selangor. The study was conducted to clarify the types of menstrual disorder among female students. The study also was aimed to identify the symptoms of menstrual disorder experience among female students before and during their menstruation and to determine the effect of menstrual disorder among female students towards their quality of life. Data from 74 respondents were used for the statistical analysis. The data were collected by using non purposive sampling. Questionnaires were used to obtain data for this study and the data for this study were analysed by using Microsoft Excel Software. Results showed that, menstrual disorder give impacts towards female quality of life. Future research should emphasize on other scope of study and more research about menstrual disorder may help organization to increase their performance and knowledge about female and their menstruation.
\end{abstract}

Keywords: menstrual disorder, female students and effects, quality of life

\section{Introduction}

The history reported contains a wide range of reproductive and menstrual myths in women. In ancient times, menstruating women are generally thought to have an evil spirit. Aristotle, which is the Greek philosopher, Plato student, he said that "menstrual women could dull a mirror with a glance, and that they would be enchanted by the next person to peer into it" (Fritz and Speroff 2011). Historia Naturalis in Latin words (natural history), a resource used throughout the Dark Ages, Pliny wrote extensively about menstruation, including:

"Contact with it makes wine sour, the plants it hits are unfruitful, the grafts die, the seeds in the gardens are dried up, the fruit of the trees drop off, the steel edge and the ivory glow dull, bee hives die, both bronze and iron are seized with rust at once, and horrible smell fills the air, to taste it causes mad dogs to infect their bites with an incurable poison. If a woman strips herself naked while she's menstruating and walks around a wheat field, caterpillars, worms, beetles and other corn ears will fall off. All plants turn a yellow taint on a woman's approach who has her menstrual discharge. Bees are going to abandon their hives at her touch because they have a peculiar

\footnotetext{
*Coordinator, Physical Education \& Health Department, Universiti Teknologi MARA Selangor (UiTM), Malaysia.

${ }^{ \pm}$Senior Lecturer, Physical Education \& Health Department, Universiti Teknologi MARA Selangor (UiTM), Malaysia.

${ }^{\sharp}$ Teacher, Physical Education \& Health Department, Universiti Teknologi MARA Selangor (UiTM), Malaysia.
} 
aversion to a thief and menstrual female, and a glimpse of her eyes is enough to kill a swarm of bees" (Elder 2009).

The fear of blood release many ancient taboos throughout early history. Menstruating women have been divided almost exclusively and prohibited from handling food. During menstruation, many primitive people found women to be unclean, subjecting them to segregation and special rituals. Therefore, it is not shocking that negative attitudes towards menstruation persisted in modern times, even with growing sophistication (Fritz and Speroff 2011). In $19^{\text {th }}$ and early $20^{\text {th }}$ century Europe, antisocial behaviour was commonly associated with menstruation. In 1845, a domestic servant who killed one of her employer's children was acquitted due to obstructed menstruation on grounds of insanity (Fritz and Speroff 2011).

Puberty is a time of intellectual, physical and emotional change for adolescents and their families. Menstruation occurs in under the influence of the hypothalamicpituitary ovarian axis due to cyclical hormonal changes (Theophilus et al. 2010). Women's menstruation is one proof that women's reproductive potential is fully developed. These menstrual cycle and period are controlled by two hormones such as oestrogen and progesterone. Removal of oestrogen and progesterone is initiated by menstruation. The effect can be experimentally produced and female who accepts these hormones in the form of a contraceptive pill or hormone renewal therapy will experience a "withdrawal lose blood" at the end of the pack (Monga 2006). The onset of puberty and menarche takes place at a time when many children are still attending school and many women are unprepared for it. The knowledge they provide is often restricted and tabooed. The education sector also avoids the issue by treating it as a private matter or a family concern which needs to be addressed. The researchers also mentioned that, many young girls lack adequate and adequate menstrual hygiene information that can lead to menstrual behavior that is incorrect and unhealthy. For some girls, the transition to adulthood is often experienced with anxiety and fear due to lack of menstrual knowledge and lack of resources to manage their menstrual activities properly (WaterAid 2012). Nevertheless, through leaving schoolgirls unprepared for this crucial phase of life, girls get overwhelmed and ignored, which in effect affects the performance of their learning and in some cases it can lead directly to school absenteeism (UNESCO 2014).

Puberty in women is the period where the secondary sexual characters evolve and the capacity to reproduce sexually is achieved (Khosla 2003). Therefore, the pubertal development especially in girls requires 4-5 years. These include the breast development, pubic and Axillary hair growth, growth spurt and menarche or the menstruation started. There is a mechanism with a maturation of the hypothalamo-pituitary ovarian axis happens. The first one is the sensitivity of low estrogen levels to the negative or inhibitory effect decreases in early puberty. Second is, increased production of Gornadotropin Releasing Hormones (GnRH) pulses results in increased levels of Follicle Stimulating Hormone (FSH) and Lutein Hormone (LH) especially during the night (Khosla 2003). There are two conditions of the menarche which are, any menarche happen before 10 years of age is a premature menarche. Meanwhile, if the menarche is not happening by 16 
years age it is called delayed menarche. The initiation of menstruation, known as menarche, usually happens between 12 and 15 years of age and continues to age between 45 and 50 when menopause occurs. Many women are afraid to discuss menstruation's existence and normality (Menstrual Cycle Physiology 2006). According to the researchers, the word "menstruation" was replaced by indirect expressions such as: "curse", "my time", "my monthly", "friend of mine", "red flag" or "grass". The beginning of menstruation is the most obvious external occurrence which signals the end of a cycle and the beginning of a new one that is widely accepted criteria for determining what is usual and unusual or normal or abnormal are generally based on what is considered the most and not necessarily typical for every woman (Durnell Schuiling and Likis 2016). Since the ancient past, the temporal relationship between the menstrual cycles and the lunar phases influenced menstrual names such as "period". The regularity of the menses was easily recognized by the ancients, even though they had no comprehension of their origin or intent.

The menstrual cycle is an excellent model for many researchers to affect the feeling, actions and cognition of ovarian steroids (Poroma and Gingnell 2014). Menstrual problems or also known as menstrual disorder in some women that may give impacts in personal relationship, physical and health activity, social activity and their daily routine. Menstrual cycle disorder is one of women's most common reasons for attending their doctor in general regarding their menstrual problems and then a gynecologist. Though life threatening rarely, menstrual disorder can lead to major cultural, occupational disruption and mental well-being as well (Mong 2006). Menstrual disorder can occur or take many forms, such as, abnormal or irregular bleeding, amenorrhea, dysmenorrhea, premenstrual syndrome, and premenstrual dysphoric disorder. Approximately 2-10\% of women of childbearing age have serious premenstrual symptoms and $2-5 \%$ meet menstrual dysphoric disorder (MDDD) requirements (O'Brien et al. 2011). The etiquette encourages management of blood and menstrual discomfort to be discreet and communicates to girls the importance of hiding their experiences of menstruation, and their status as a menstruating girl, from boys and men (Sommer et al. 2015).

Research conducted through numerous countries and contexts shows the paternal existence of many school settings, with menstruating girls unable to properly manage their monthly menses with protection, integrity and confidentiality (UNICEF 2015). According to Otwani and Juma (2017), approximately among $52 \%$ of the population of female of their age of reproductive, which means menstruation is part of the normal life of female. Therefore, menstrual cleanliness is the important part of the basic cleanliness practices. Big biological changes such as physical growth, sexual maturation and psycho-social development in adolescence define the changes from childhood to adulthood, an age group defined by the World Health Organization (WHO) as 10-19 years old (Tarhane and Kasulkar 2015). The researcher also states that, adolescence is defined by increased food requirements, increased metabolic and biochemical basal activities, endogenous processes such as hormonal secretions with their effect on the various organs, the most significant of which is menarche or known as the first of menstruation in adolescent girls. 
This research will determine the types of menstrual disorder among female students, to identify the symptoms of menstrual disorder experience among female students and to determine the effect of the menstrual disorder towards quality of life.

\section{Literature Review}

Nowadays, some women often get upset when comes to menstrual problems. When women face this problem, some women get their solutions by take pills or herbal medicine. In fact, women need to know in advance why their menstrual cycle is problematic and then seek treatment instead of taking pill. This phenomenon might happen, because women lack basic knowledge about their types of menstrual disorder.

Past studies indicate that in several measures of quality of life, women with menstrual symptoms have lower scores, including general health and physical, mental, social and occupational functioning (Schoep et al. 2019a). The researchers also added that, symptoms include dysmenorrhea 45\%-90\%, heavy menstrual bleeding $14 \%-25 \%$ and premenstrual mood disturbances with reported prevalence 20\%-29\% respectively. These symptoms can give impacts towards female student's quality of life which is productivity lost could be the largest cost driver. Costs of productivity can be split into costs of absenteeism and presenteeismrelated costs.

Menstrual signs have an important impact on quality of life, according to Schoep et al. (2019b). The result of the research was between $22.5 \%$ and $35 \%$ of women consider having the severe menstrual bleeding, 34\%-94\% experience pain during their menstrual period. In younger women, especially a student, the absence of menstrual signs from school or lower performance levels. A female student who is not attending school due to dysmenorrhea ranges from $7.7 \%$ to $57.8 \%$, while $21.5 \%$ are lack social activities (Schoep et al. 2019b). A menstrual problem is a physical or emotional issue that interferes with the regular menstrual cycle, causing pain, excessively extreme or moderate bleeding, prolonged menarche (the first occurrence of menstruation) or missing periods (Gale 2015).

Besides that, based on previous research, the researcher found that women need to increase the awareness regarding menstrual problems. This statement was supported by Kansal et al. (2016). It was found from the Focus Group Discussion (FGDS) as well as from the quantitative survey that the knowledge of menarche was still low in rural areas before its establishment. The researcher found that, one of the ways to increase their awareness about menstrual is through education. Sex education Curriculum is important to give the basic knowledge towards the students. Therefore, there is also a need to provide parents with intensive family life education (Kansal et al. 2016).

According to Schoep et al. (2019b), from studies in patients with endometriotic and premenstrual disorder, it has shown that these symptoms can have a large impact on women's quality of life and account for substantial health care use. The researchers also mentioned that, the result of the symptoms of menstrual disorder 
can cause the productivity loss among students such as absenteeism and low of concentration or focus in the class. In addition, the result also shows that, during menstrual disorder women reported doing fewer tasks or were unable to do anything during their periods. Most families reported at least one menstrual or premenstrual symptom, many of which were severe and caused about $20 \%$ of girls to frequently have problems at home or miss school (Kaskowitz et al. 2016).

According to Poroma and Gingnell (2014), research examining menstrual cycle effects on tasks that measure prefrontal cortex control, such as verbal or spatial working memory, in addition to sexually dimorphic cognitive skills. This may cause many women suffer from their emotion during menstrual cycle. Schoep et al. (2019a) stated that women with menstruation-related symptoms have lower scores in several areas of quality of life during their cycles, such as general health and physical, emotional, social and occupational function. In addition, these symptoms may result considerable financial burdens on patients and their families as well as on society. Also, De Sanctis et al. (2016) reviewed studies on dysmenorrhea in multiple countries, some of which included menstruation-related absenteeism data and they found that the prevalence of school absences in adolescents that was due to dysmenorrhea varied between $7.7 \%$ and $57.8 \%$.

Menstrual problems in some adolescents may lead to disruptions in personal relationships and school activities and reduction in academic performance (Theophilus et al. 2010). The researchers also add that emotional anxiety due to academic or social demands may act as cofactors. While $89 \%$ of respondents perceived menstruation as a normal body function for women, $18 \%$ of respondents felt it was wrong to go to school while they were menstruating (Otwani and Juma 2017). In addition, $30 \%$ of them felt that it is wrong to play or doing some exercise and most of them spend their recreation time with sleeping under the trees.

There is proof that menstrual cycle-related symptoms lead to and disengage employment, social relationships and physical activity issues (Lerser et al. 2016). For example, research has shown it is often correlated with school absenteeism and decreased school performance the painful menstruation (dysmenorrhea) and other menstrual cycle-related physical symptoms (Steiner et al. 2011). The researchers also mentioned that girls of some adolescents with menstruation limit their contact with peers and have difficulties with social relationships. In particular, the current results indicate that physical symptoms decrease incentives for normal and significant developmental activities, including work, sports, and time spent with friends, which may result in repeated or persistent negative (Lerser et al. 2016).

The effects of the menstrual disorder were rated from mild to moderate to severe. The concept of mild symptoms did not limit daily activity. Symptoms are considered moderate if there were obvious regular limitations and extreme if the participants were unable to conduct the tasks without discomfort (Buddhabunyakan et al. 2017). 


\section{Methodology}

This study is descriptive research which a type of quantitative research. About observed data by organizing, presenting and summarizing data. It is concerned with describing something that has already occurred (Singh et al. 2009). Meanwhile the questionnaire survey is used for acquiring data as a finding for this study. From the questionnaire that is distributed, all information that should be included in this research proposal will be obtained. In addition, the questionnaire that been distributed is closed questions where by the respondents may answer questions in which the answers given by them may be helpful in some way to provide researcher useful information to be inserted in the research proposal.

\section{Research Design}

This study is a descriptive research which this is a type of quantitative research. The quantitative research involves a bit of calculation in order to obtain results from the questionnaire that been distributed. In addition, from the answers obtained from the questionnaires that distributed will be measured or counted. The questionnaire will be distributed to the female students which from Physical and Heath education program, Faculty of Education University of Technology Mara (UITM) in semester September-January 2019.

\section{Population and Sampling}

The population and sampling design that used in this study as stated below.

\section{Population}

In this study, a set of target population for female students from Physical and Health education program. The female students in Physical and Health education include 90 students in semester September-January 2019.

\section{Sampling}

Based on Table 1, this study was use purposive sampling. Purposive sampling is used as the method because it is small group and can be easily measured. Purposive sampling is the process whereby a group of subjects is chosen as respondents because they have certain characteristic (Piaw 2016). From 90 students estimated population size, the sample at least 73 respondents.

Table 1. Sampling

\begin{tabular}{|l|l|c|}
\hline Faculty of Education & $\begin{array}{l}\text { Estimated } \\
\text { Population }\end{array}$ & Sample \\
\hline $\begin{array}{l}\text { Female students in Physical and Health } \\
\text { Education Program }\end{array}$ & 90 Students & $\begin{array}{c}73 \\
\text { Respondents }\end{array}$ \\
\hline
\end{tabular}

Source: Krejcie and Morgan's sample size determination table 1970. 


\section{Instrumentation}

To perform the survey, questionnaire will be distributed to students from Faculty of Education that study in UITM, at Puncak Alam. A set of 73 questionnaires will be distributed to the samples. Questionnaires is used as a data gathering method because it would be the best choice for the instrument of conducting survey as the result of the findings may be calculated with computing software and at the same time, it may reduce some biases.

\section{Data Collection Method}

This study used questionnaire-based survey for data collection method. Compared with other collection methods questionnaire is selected to be used as a data collection method because it is easier to reach many respondents. The questionnaire that distributed will use the close ended questions where by the respondents only answer the questions based on the answer that already been stated in the questionnaire sheets. The close ended questionnaires that will be distributed include checklist, rating scale, and agree-disagree answer.

\section{Data Analysis Procedures}

All data that been gathered will compute by using the Microsoft Excel software and it is a comprehensive and systematic data analysis and for data management system. The Microsoft Excel can calculate data from almost any type and it even can be used to tabulate reports, charts, and as well as it can conduct complex statistical analysis. The data then will be translated into useful means and modes for identifying certain stated hypotheses.

\section{Results}

\section{Profile of Respondents}

The first section in this questionnaire consists of four (4) questions about the respondents' demographic information to answer the question on their background information such as age, current semester, age of menarche (the first occurrence of Menstruation) and the duration of their menstrual cycle. Table 2 shows the respondents' demographic profile information: 
Table 2. Respondents' Demographic Profile Information

\begin{tabular}{|l|c|c|}
\hline Criteria & Frequency (n) & Percentage (\%) \\
\hline Age & 28 & 37.8 \\
\hline $20-22$ years & 29 & 39.2 \\
\hline $22-24$ years & 17 & 23.0 \\
\hline $24-26$ years & 74 & 100 \\
\hline Total & 12 & 16.2 \\
\hline Current Semester & 7 & 9.5 \\
\hline Semester 1 & 8 & 10.8 \\
\hline Semester 2 & 20 & 27.0 \\
\hline Semester 3 & 10 & 13.5 \\
\hline Semester 4 & 12 & 16.2 \\
\hline Semester 5 & 5 & 6.8 \\
\hline Semester 6 & 74 & \\
\hline Semester 8 & & \\
\hline Total & & \\
\hline $\begin{array}{l}\text { Age of menarche (first } \\
\text { occurrence of } \\
\text { menstruation) }\end{array}$ & 40 & 54.1 \\
\hline $10-12$ years & 31 & 41.9 \\
\hline $13-15$ years & 3 & 4.1 \\
\hline $15-17$ years & 74 & \\
\hline Total & & 1.4 \\
\hline Duration of menstrual cycle & 1 & 86.5 \\
\hline $1-3$ days & 64 & 12.2 \\
\hline 1 week & 9 & \\
\hline 2 weeks & 74 & \\
\hline Total & & \\
\hline
\end{tabular}

Based on Table 2, respondents that are participating in this study were from 20 years to 26 years. From 74 respondents above, there are 28 respondents who are in the age of 20-22 years old (37.8\%), 29 respondents in the age of 22-24 years old $(39.2 \%)$. Meanwhile, respondents in the age of 24-26 years old (23\%).

Table 2 shows that $16.2 \%$ of the respondents are from semester 1 equal to 12 respondents, $9.5 \%$ from semester 2 equal to 7 respondents, $10.8 \%$ from semester 3 equal to 8 respondents. Meanwhile, $27 \%$ from semester 4, which consists of 20 respondents. $13.5 \%$ from semester 5 equal to 10 respondents, $16.2 \%$ from semester 6 consists of 12 respondents and for semester 8, 6.8\% equal to 5 respondents.

Table 2 also shows the respondent's age of their menarche or the first occurrence of their menstruation. It shows that most of the respondents $54.1 \%$ were had their menarche at 10 to 12 years old equal to 40 respondents. 31 respondents equal $41.9 \%$ were had their menarche at 13 to 15 years old, followed by 3 respondents equal $4.1 \%$ were had their menarche at the age of 15 to 17 years old.

In terms of respondent duration of menstrual cycle, it is shown that only 1 respondent choose the duration of menstrual cycle in 1 to 3 days (1.4\%), for 64 respondents $(86.5 \%)$ choose their duration of menstrual at 1 weeks and 9 respondents $(12.2 \%)$ choose their duration of menstrual cycle for 2 weeks. 
Types of Menstrual Disorder

Table 3. Descriptive Statistics of Types of Menstrual Disorder

\begin{tabular}{|c|c|c|c|c|c|c|}
\hline & $\begin{array}{l}\text { Abnormal } \\
\text { Uterine } \\
\text { Bleeding }\end{array}$ & Amenorrhea & Oligomenorrhea & $\begin{array}{l}\text { Premenstrual } \\
\text { Syndrome } \\
\text { (PMS) }\end{array}$ & $\begin{array}{c}\text { Premenstrual } \\
\text { Dysphonic } \\
\text { Disorder } \\
\text { (PMDD) }\end{array}$ \\
\hline \multirow{2}{*}{$\mathrm{N}$} & Valid & 74 & 74 & 74 & 74 & 74 \\
\hline & Missing & 0 & 0 & 0 & 0 & 0 \\
\hline \multicolumn{2}{|c|}{ Mean } & 2.04 & 1.72 & 1.97 & 3.82 & 3.01 \\
\hline \multicolumn{2}{|c|}{ Median } & 2.00 & 1.00 & 2.00 & 4.00 & 3.00 \\
\hline \multicolumn{2}{|c|}{ Mode } & 1 & 1 & 1 & 4 & 3 \\
\hline \multicolumn{2}{|c|}{ Std. Deviation } & 1.053 & 0.944 & 0.950 & 0.942 & 1.233 \\
\hline
\end{tabular}

Table 3 shows the result of the types of menstrual disorder that most experience by the female students, from Physical and Health Education. The highest mean indicates the most type that experience by the female students. 3.84 mean experience the most is the Premenstrual Syndrome (PMS). While the lowest mean is 1.72 which is the Amenorrhea. The mean for Abnormal Uterine Bleeding is 2.04, Oligomenorrhea 1.97 and Premenstrual Dysphonic Disorder (PMDD) is 3.01. The highest median also the type of Premenstrual Syndrome (PMS) which 4.0, and the lowest median were Amenorrhea which is 1.0. The median for Abnormal Uterine Bleeding is 2.0, Oligomenorrhea is 2.0 and Premenstrual Dysphonic Disorder (PMDD) is 3.0. For mode, Abnormal Uterine Bleeding, Amenorrhea and Oligomenorrhea have the same mode which is 1.0. While the highest mode is Premenstrual Syndrome (PMS) (which is 4) and the mode for Premenstrual Disorder (PMDD) is 3. Therefore, the standard deviation for Abnormal Uterine Bleeding is 1.053, Amenorrhea is 0.944, Oligomenorrhea 0.950, Premenstrual Syndrome (PMS) is 0.942 and 1.233 for PMDD.

The Symptoms during that Time (before Menstrual) and Symptoms for Today (during Menstrual)

Table 4. Paired Sample Result

\begin{tabular}{|l|l|c|c|c|c|}
\hline \multicolumn{2}{|c|}{} & Mean & N & Std. Deviation & $\begin{array}{c}\text { Std. Error } \\
\text { Mean }\end{array}$ \\
\hline \multirow{2}{*}{ Pair 1 } & Section C1 & 31.34 & 74 & 6.488 & 0.754 \\
\cline { 2 - 6 } & Section C2 & 35.2568 & 74 & 8.44492 & 0.98170 \\
\hline
\end{tabular}

Several statistics are presented in the first table using Paired Samples Statistic (Table 4). The examination of these means suggests that the average symptoms that are experienced by female students were higher during their menstruation.

Table 5. Paired Samples Correlations

\begin{tabular}{|l|c|c|c|}
\hline & N & & Sig. \\
\hline Pair 1 Section C1 \& Section C2 & 74 & 0.482 & 0.000 \\
\hline
\end{tabular}


The paired-samples t-test procedure automatically computes the correlation between the two sets of section. From Table 5, we can see that there is no significant positive correlation between the section which are before and during menstruation $(\mathrm{r}=0.754)$, indicating that most of the respondents experience the symptoms during their menstruation.

Table 6. Paired Samples Test

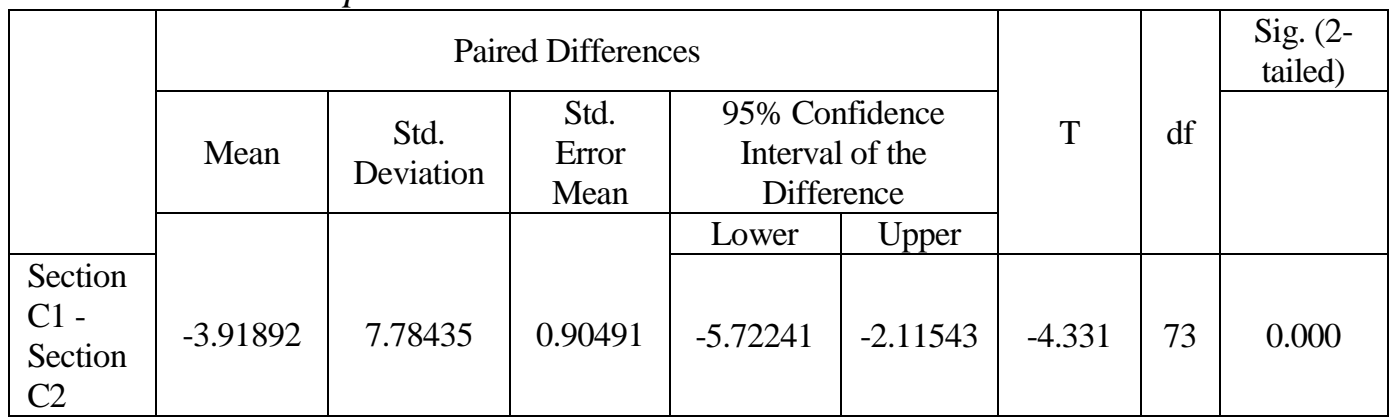

Based on Table 6, presents the results of the t-test. The first column shows the actual difference between two means (-3.92), which is the numerator of the t-test formula. This shows that a negative number because the mean after the menstruation is a larger value and subtracted from before the menstruation which is a smaller value.

\section{The Effects of Menstrual Disorder towards Female Quality of Life}

Table 7. The Effects of Menstrual Disorder towards Female Quality of Life

\begin{tabular}{|l|l|c|c|}
\hline $\begin{array}{l}\text { Questions } \\
\text { Number }\end{array}$ & \multicolumn{1}{|c|}{ Statements } & Mean & SD \\
\hline 34. & $\begin{array}{l}\text { There is lowered school or work performance during } \\
\text { my menstruation. }\end{array}$ & 3.22 & 1.037 \\
\hline 35. & $\begin{array}{l}\text { Menstruation problem limits me in performing } \\
\text { everyday living activities. }\end{array}$ & 3.42 & 1.034 \\
\hline 36. & $\begin{array}{l}\text { I lost my concentration and low in performance for } \\
\text { educational system. }\end{array}$ & 3.35 & 1.254 \\
\hline 37. & $\begin{array}{l}\text { Menstrual problems can limit my physical activity } \\
\text { such as sport. }\end{array}$ & 3.53 & 1.063 \\
\hline 38. & $\begin{array}{l}\text { Often suffer from menstruation can affect my life to } \\
\text { be meaningful. }\end{array}$ & 3.23 & 1.188 \\
\hline 39. & $\begin{array}{l}\text { Often suffer from menstruation can affect my } \\
\text { emotion and easily irritated by others. }\end{array}$ & 3.51 & 1.037 \\
\hline 40. & $\begin{array}{l}\text { I will avoid social activities during my menstruation } \\
\text { because of discomfort feelings. }\end{array}$ & 3.68 & 1.022 \\
\hline 41. & $\begin{array}{l}\text { I prefer to sleep and stay in my bed during my } \\
\text { menstruation. }\end{array}$ & 3.82 & 1.052 \\
\hline 42. & $\begin{array}{l}\text { I am suffering from sleepiness during menstruation. } \\
\text { I can't manage my time easily due to changing my } \\
\text { pad or tampon frequently. }\end{array}$ & 3.26 & 1.304 \\
\hline 43. & & 3.26 & 1.415 \\
\hline
\end{tabular}


The effects of menstrual disorder were used to determine the quality of life among female students in physical and health education. Table 7 shows that the highest mean that give effects towards female quality of life is 3.82 which is (I prefer to sleep and stay in my bed during my menstruation). The second highest is 3.68 which is (I will avoid social activities during my menstruation because of discomfort feelings) and third is 3.52 which is (Menstrual problems can limit my physical activity such as sport). The lowest mean that give effects towards female quality of life is 3.22 which is (There is lowered school or work performance during my menstruation). The second is 3.23 which is (Often suffer from menstruation can affect my life to be meaningful). While third is 3.26 which is (I am suffering from sleepiness during menstruation). The highest standard deviations are 1.415 and the lowest were 1.034 .

\section{Discussion}

\section{Types of Menstrual Disorder}

Every month female or women will have their menstrual. To reach the menstrual cycle is a proof to a woman as the phase of maturation. Some woman may experience a problem with their menstruation which can affect the daily routines. Menstrual only comes a month, but some women may experience that no menstruation for a few months, or there is a woman experience a prolonged duration of menstruation. Some women complaints and refer to the doctors, but some woman tend to handle the menstrual problems by their own-self. During conducting this research, the researcher had asked several respondents about the types of their menstrual problem and most of them is not sure and some of them do not know that the menstrual problems that they face is regarding the types of menstrual disorder. There are several types of menstrual disorder such as PMS, PMDD, Abnormal Uterine Bleeding, Oligomenorrhea and Amenorrhea.

From the analysis of data collected reveal that, most of female students in UItm Puncak Alam having the types of PMS equal to 3.83 mean. The second types that are often experienced by female students is PMDD and equals to 3.01 mean. The moderate types of menstrual disorder that are experienced by women is Abnormal Uterine Bleeding and equals to 2.04 mean. Meanwhile, the lowest mean that indicates the type of experience by the female is Amenorrhea or also known as the absence of menstrual bleeding equal to 1.72 mean. There is still lack of knowledge among female students in University regarding their menstrual problems. Most of the respondents stated the general types of "menstrual problem", but lack of knowledge on the specific types of menstrual disorder.

As mentioned before, Abnormal Uterine Bleeding is a type of menstrual problems that is excessive or prolonged menstrual bleeding, Amenorrhea is a type of menstrual problem which is the absence of menstrual bleeding. Oligomenorrhea is a type of infrequent menstruation or light that experience by the female students, and the most and often experience by women is PMS, a type of physical and emotional discomfort due to prior menstruation. And the last type is PMDD which 
is a type of severe physical and emotional discomfort due to prior menstruation. Based on the previous research, the types of menstrual disorder that the female may face is affecting by the age of menarche (Kaskowitz et al. 2016).

\section{Symptoms of Menstrual Disorder}

According to findings, there is a significant correlation between the symptoms before and during their menstruation. Most of the respondents is experiences their PMS and some of them were experiences the symptoms of menstruation problems during their menstrual cycle. The highest percentage of the symptoms that the respondents experience is the one of the easily irritability. Frequency $(n=23)$ and the percentage is $31.1 \%$. This can happen either before the menstruation of before the menstruation. Some woman indicates that, the feel irritates when somethings affect their emotions. This symptom may change due to hormone system in the body function. The lowest score this symptom is $(n=9)$ equal to $12.2 \%$ which is experience acute by some women.

The second symptom that is often experienced by female students is the easily mood swings. According to findings, the frequency $(n=25)$ and the percentage is $33.8 \%$. These symptoms have the relationship between easily irritated. When woman feel irritated by someone or things that they can't do, it is can make the woman got their mood swing. The researcher had some discussion by women during conducting the research, and the researcher found out that, the mood swings can be worst during their menstrual cycle. During the day that the women not in their menstruation, all things they do is went well, they can wait for things, they can be nice to people, but when it comes to their menstrual cycle either before or during small matters can be the big issues. This is what we call as a speciality of women and no one can describe that. Some people agree that, it is a natural way of being women. But there is also a woman that no experience of the symptoms which the frequency is $(\mathrm{n}=5)$ and the percentage is $6.8 \%$.

The third symptom that is often experienced by female students is a change in their eating habits. The frequency of the respondents in this symptom is $(n=23)$ equal to $31.1 \%$. The eating habits may divide into two parts. The first one is eating too little and second is eating too much. Both of this can give a warning sign to the female body that is not functioning properly. During conducting the research, the respondents had stated that this symptom was high experience before their menstruation. And they experience it moderate during their menstruation. Some women think that, this eating habit is a normal, but there is a respondent indicates that, their symptoms of eating disorder make them feel acute of uncomfortable $(n=13)$ equal to $17.6 \%$.

\section{Effects of Menstrual Disorder towards Female Quality of Life}

Menstrual disorder can give impact to the female quality of life. This is due the severity of the symptoms that the respondents may experience. As mentioned before, the researcher had stated the types of menstrual disorder and the symptoms of menstrual disorder that affect the female quality of life. There are 10 questions 
been asked with 5 different answers that indicate their experience of. Between the 10 questions, the highest statements that give impact towards their daily routine is they prefer to sleep and stay in their room during their menstruation. The mean of this data is 3.82. The percent of the respondents is $40.5 \%$. This can lead in absence from the school or lower score in education performance. According to Schoep et al. (2019b), a young female that may experiences the severity of the symptoms may result in not attending school and can lead to reduction in academic performance.

In addition, second highest mean is 3.68 which the respondents indicate that they will avoid social activities during their menstruation because of discomfort feeling. The percentage of the respondent is $41.9 \%$. One of the types of quality of life that the researcher seeks to is the changes of behaviour towards female with menstrual disorder. Therefore, this result shown that, there is a change in female behaviour due to menstrual disorder. The symptoms of the menstrual disorder lead to worst of feeling to the woman until she can't do anything. If the woman having the type of Abnormal Uterine Bleeding which is 3 weeks duration of menstrual, it can give negative change in the woman life.

The third highest mean is 3.53 which is menstrual problems can limit female students physical of activity such as sport. The highest percentage of this statement is $40.5 \%$. One of the highest symptoms that been experience of respondents is cramps on their abdominal part. When they experience this kind of symptom, it is can limit the movement of the female students.

\section{Conclusion}

The researcher found that impact of menstrual disorder towards females' quality of life is considerable. Parents should educate girls about what to expect of a first menstrual period and the range for normal cycle length of subsequent menses. Once girls begin menstruating, clinicians should ask at every preventive care or comprehensive visit for the patient's first day of her last menstrual period and the pattern of menses. Identification of abnormal menstrual patterns in adolescence may improve early identification of potential health concerns for adulthood. It is important for parents to have an understanding of the menstrual patterns of adolescent girls, the ability to differentiate between normal and abnormal menstruation, and the skill to know how to evaluate the adolescent girl patient. It is hoped that this research able to helps those people who are interested in exploring the impact of menstrual disorder towards female quality of life.

\section{References}

Buddhabunyakan N, Kaewrudee S, Chongsomchai C, Soontrapa S, Somboonporn W, Sothornwit J (2017) Premenstrual syndrome (PMS) among high school students. International Journal of Women's Health 9(Jul): 501-505.

De Sanctis V, Soliman AT, Elsedfy H, Soliman N, Elalaily R, El Kholy M (2016) Dysmenorrhea in adolescents and young adults: a review in different country. Acta Bio-medica: Atenei Parmensis 87(1): 0-0. 
Durnell Schuiling K, Likis FE (2016) Women's gynecologic health. London: Jones and Bartlett Learning.

Elder PT (2009) The natural history. Chicago: University of Chicago.

Fritz MA, Speroff L (2011) Clinical gynecologic endocrinology and infertility. USA: Library of Congress Cataloging.

Gale (2015) The Gale encyclopedia of medicine. $5^{\text {th }}$ Edition. US: Gale.

Kansal S, Singh S, Kumar A (2016) Menstrual hygeine practices in context of schooling: a community study among rural adolescent girls in Varanasi. Indian Journal of Community Medicine Volume 41(1): 39-44.

Kaskowitz AP, Dendrinos M, Murray PJ, Quint EH, Ernst S (2016) The effect of menstrual issues on young women with angelman syndrome. Journal of Pediatric and Adolescent Gynecology 29(4): 348-352.

Khosla AH (2003) Quick revision in gynaecology. New Delhi: Jitendar P Vij.

Lerser K, Kiesner J, Pastore M, Scholte R (2016) The impact of menstrual cycle related physical symptoms on daily activities and psychological wellness among adolescent girls. Journal of Adolescence 49(Jun): 81-90.

Monga A (2006) Gynaecology by ten teachers. Edited by S Dobbs. Southampton: Edward Arnold Publishers Ltd.

Nwanko TO, Aniebue UU, Aniebue PN (2010) Menstrual disorder in adolescent school girls in Enugu, Nigeria. Journal of Pediatric and Adolescent Gynecology 23(6): 358363.

O’Brien PMS, Bäckström T, Brown C, Dennerstein L, Endicott J, Epperson N (2011) Towards a consensus on diagnostic criteria, measurement and trial design of the premenstrual disorder. Archive of Women's Mental Health 14(1): 13-21.

Otwani C, Juma D (2017) Determinants of menstrual hygiene among primary school girl projects in Nambale division of Busia County, Kenya. International Journal of Scientific Engineering and Research (IJSER) 2(3): 105-113.

Piaw CY (2016) Mastering research method. Shah Alam: McGraw-Hill Education (Malaysia) Sdn. Bhd.

Poroma IS, Gingnell M (2014) Menstrual cycle influence on cognitive function and emotion processing: from a reproductive perspective. Frontiers in Neuroscience 8(Nov): 380.

Schoep ME, Adang EMM, Maas JWM, De Bie B, Aarts JWM, Nieboer TE (2019a) Productivity loss due to menstruation-related symptoms: a nationwide cross-sectional survey among 32,748 women. BMJ Open 9(6): e026186.

Schoep ME, Nieboer TE, van der Zanden M, Didi DM, Braat MD, Nap AW (2019b) The impact of menstrual symptoms on everyday life: a survey among 42,879 women. American Journal of Obstetrics and Gynecology 220(6): 569.e1-569.e7.

Singh P, Ghani PA, Hoon TS (2009) Quantitative data analysis for novice researchers. Kuala Lumpur: Primera Publishing.

Sommer M, Hirsh JS, Nathanson C, Parker RG (2015) Comfortably, safely and without shame: defining menstrual hygiene management as a public health issue. American Journal of Public Health 105(7): 1302-1311.

Steiner M, Peer M, Palova E, Freeman EW, Macdougall M, Soares CN (2011) The premenstrual symptoms screening tool revised for adolscents (PSST-A): prevalence of severe PMS and premenstrual dysphoric disorder in adolescents. Archive Women's Mental Health 14(1): 77-81.

Tarhane S, Kasulkar A (2015) Awareness of adolescent girls regarding menstruation and practices during menstrual cycle. Panacea Journal of Medical Science 5(1): 9-32.

UNESCO (2014) Puberty education \& menstrual hygiene management good policy and practice in health education. Booklet 9. UNESCO. 
UNICEF (2015) WASH in schools empower girls: education proceedings of the menstrual hygiene. In Management in Schools Virtual Conference 2014. UNICEF.

WaterAid (2012) A resource for improving menstrual hygiene management around the world. United Kingdom: WaterAid. 
